\title{
Particle Mass Concentrations and Number Size Distributions in 40 Homes in Germany: Indoor-to-outdoor Relationships, Diurnal and Seasonal Variation
}

\author{
Jiangyue Zhao', Wolfram Birmili², Birgit Wehner ${ }^{1}$, Anja Daniels ${ }^{2}$, Kay Weinhold ${ }^{1}$, Lina Wang ${ }^{4}$, \\ Maik Merkel$^{1}$, Simonas Kecorius ${ }^{1}$, Thomas Tuch${ }^{1}$, Ulrich Franck ${ }^{3}$, Tareq Hussein ${ }^{5,6}$, \\ Alfred Wiedensohler ${ }^{*}$
}

\author{
${ }^{1}$ Leibniz Institute for Tropospheric Research, 04318 Leipzig, Germany \\ ${ }^{2}$ German Environment Agency (UBA), 14195 Berlin, Germany \\ ${ }^{3}$ Helmholtz Centre for Environmental Research, 04318 Leipzig, Germany \\ ${ }^{4}$ Department of Environmental Science and Engineering, Fudan University, Shanghai 200433, China \\ ${ }^{5}$ University of Jordan, Amman 11942, Jordan \\ ${ }^{6}$ Institute for Atmospheric and Earth System Research, University of Helsinki, 00560 Helsinki, Finland
}

\begin{abstract}
Few studies investigated residential particle concentration levels with a full picture of aerosol particles from $10 \mathrm{~nm}$ to $10 \mu \mathrm{m}$ size range with size-resolved information, and none was performed in central Europe in the long-term in multiple homes. To capture representative diurnal and seasonal patterns of exposure to particles, and investigate the driving factors to their variations, measurements were performed in 40 homes for around two weeks each in Leipzig and Berlin, Germany. These over 500 days' measurements combined $\mathrm{PM}_{10}$ and $\mathrm{PM}_{2.5}$ mass concentrations, particle number concentration and size distribution ( $\mathrm{PNC}$ and PNSD, $10-800 \mathrm{~nm}$ ), $\mathrm{CO}_{2}$ concentration, and residential activities diary into a unique dataset. Natural ventilation was dominated, the mean ventilation rate calculated from $\mathrm{CO}_{2}$ measurements was $0.2 \mathrm{~h}^{-1}$ and $3.7 \mathrm{~h}^{-1}$ with closed and opened windows, respectively. The main findings of this study showed that, the residents in German homes were exposed to a significantly higher mass concentration of coarse particles than outdoors, thus indoor exposure to coarse particles cannot be described by outdoors. The median indoor PNC diurnal cycles were generally lower than outdoors (median I/O ratio 0.69). However, indoor exposure to particles was different in the cold and warm season. In the warm season, due to longer opening window periods, indoor sources' contribution was weakened, which also resulted in the indoor PNC and PNSD being very similar to the outdoors. In the cold season, indoor sources caused strong peaks of indoor PNC that exceeded outdoors, along with the relatively low penetration factor - 0.5 for all size ranges, and indoor particle losses, which was particularly effective in reducing the ultrafine PNC, resulting in a different particle exposure load than outdoors. This study provides a detailed understanding of residential particle exposure in multiple homes, facilitating future studies to assess health effects in residential environments.
\end{abstract}

Keywords: Indoor particle exposure; Indoor particle loss; Indoor source; I/O ratio; Penetration.

\section{INTRODUCTION}

Aerosol particles, or particulate matter, have attracted concerns for public health because of their association with respiratory and cardiovascular diseases (Pope III and Dockery, 2006; Brook et al., 2010). In air quality regulation, particle mass concentrations such as $\mathrm{PM}_{10}$ and $\mathrm{PM}_{2.5}$ (particles $<10 \mu \mathrm{m}$ and $<2.5 \mu \mathrm{m}$ aerodynamic diameter, respectively) are often quantified (WHO, 2006). Some epidemiological studies have,

\footnotetext{
* Corresponding author.

Tel.: +493412717 7062

E-mail address: ali@tropos.de
}

however, suggested that a major part of the adverse health effects induced by particles could go down to fine and ultrafine particles (FP and UFP, mobility diameter Dp $<1 \mu \mathrm{m}$ and $<0.1 \mu \mathrm{m}$, respectively) (Peters et al., 1997; Oberdörster, 2000; Chen et al., 2017). Moreover, the particle deposition efficiency in the respiratory tract is size-dependent (ICRP, 1994; Rückerl et al., 2011; Ohlwein et al., 2019).

In developed countries, people spend most of their time indoors, typically more than $65 \%$ at home (Brasche and Bischof, 2005; Schweizer et al., 2007; Odeh and Hussein, 2016). In residential environments, people are usually exposed to a mixture of particles originating from indoor sources (being related to cooking activities and combustion sources), and the outdoor aerosol (transported through natural ventilation, mechanical ventilation, or penetrated via cracks 
and leaks in a building) (Chen and Zhao, 2011). The indoor particle concentration diurnal cycles and size distributions depend therefore strongly on residents' activity patterns. To understand the magnitude and mechanisms of particle exposure in residential homes, it is important to measure particle mass and number concentrations (PMC and PNC, respectively), and their size distributions (PNSD and PMSD, respectively), both indoors and outdoors.

Risk assessment and model development for indoor aerosol particles is dependent on high quality field measurements (Koivisto et al., 2019). A series of residential indoor and outdoor particle studies were focused on the $\mathrm{PM}_{10}$ and $\mathrm{PM}_{2.5}$ mass concentration (Monn et al., 1997; Geller et al., 2002; Allen et al., 2003; Hänninen et al., 2004; Rodes et al., 2010; Hassanvand et al., 2014; Morawska et al., 2017). However, only relatively few studies have investigated the residential particle concentration level with a full picture of particles from $10 \mathrm{~nm}$ to $10 \mu \mathrm{m}$ size range, with sizeresolved information (Abt et al., 2000; Long et al., 2000; Diapouli, 2011; Hussein, 2017). Among them, only in the study by Diapouli (2011) the simultaneous indoor and outdoor measurements were performed in Europe, however, only included three flats. In general, there is a lack of knowledge of representative residential particle exposure levels in the long-term and in multiple European homes.

During infiltration, the outdoor particle PNSD and PMSD are modified inside the house or apartment (Morawska et al., 2001; Hussein et al., 2005) due to losses by diffusion, impaction, and gravitational settling. These sink processes are a strong function of particle size (He et al., 2005; Hussein et al., 2009b). The particle penetration (i.e., filtration and infiltration) efficiency is influenced by many factors including meteorological conditions (temperature, humidity, and pressure), window types, and residential building materials and structures (Morawska et al., 2017). Additionally, indoor particle losses are affected by the area and material of the indoor surfaces, as well as the house/apartment configuration. Therefore, every residential environment has its specific penetration and particle loss effects (Long et al., 2001; Hussein et al., 2015). Several studies have investigated residential infiltration efficiency and indoor particle loss rate via model simulations (Liu and Nazaroff, 2001, 2003; Tian et al., 2009) and via field measurement in one test house/apartment (Hussein et al., 2005; Talbot et al., 2016; Hussein, 2017; Zhao and Stephens, 2017). Long et al. (2001) quantified the penetration factor for $20-1000 \mathrm{~nm}$ size particles was $0.6-1.0$ and deposition rates were 0.1 to $0.5 \mathrm{~h}^{-1}$ in nine homes in the USA. Zhao and Stephens (2017) and Hussein et al. (2005) estimated the mean penetration factors of 10-1000 nm size particles, results ranged from 0.4 to 0.7 and from 0.2 to 0.7 , respectively. However, both of them were only measured in one home. Despite the different living conditions, apartments/ houses in Germany are relatively unified in following terms: homes are in most cases built of bricks, and most importantly, equipped with modern energy-efficient windows (under the Energy Saving Regulation "Energieeinsparverordnung" requirement) (EnEV, since 2001). Nevertheless, there is still a lack of representative observations to quantify the indoorto-outdoor relationship in multiple homes in Germany.
The scientific scope of this study was to characterize the representative diurnal and seasonal variation patterns of residential indoor and outdoor $\mathrm{PMC}$ and $\mathrm{PNC}$ in homes under real-use conditions, thereby filling a gap of the sizedependent indoor-to-outdoor relationships in residential environments. To address these goals, simultaneous indoor and outdoor measurements were performed twice in 40 private houses/apartments in Leipzig and Berlin, Germany for a minimum of ten days each during different seasons. As integral parameters, we evaluate $\mathrm{PM}_{10}, \mathrm{PM}_{2.5}, \mathrm{PM}_{1}$ mass concentrations, $\mathrm{N}_{\mathrm{FP}}$ and $\mathrm{N}_{\mathrm{UFP}}(10-800 \mathrm{~nm}$ and $10-100 \mathrm{~nm}$ mobility diameter Dp, respectively), PNSD and PMSD (10$800 \mathrm{~nm} \mathrm{Dp}$ ), and combined ambient meteorological parameters as well as information about residential activities into a unique dataset.

\section{MATERIALS AND METHODS}

\section{Measurement Sites}

Measurements were performed in 40 non-smoking homes during December 2016-December 2017 in Leipzig (Table 1, home L1 to L20), and during January 2018-March 2019 in Berlin (Table 1, home B1 to B20). Each home was measured twice: the season during measurement and days of measurement are listed in Table 1 (home L10 did not participate in the 2nd measurement).

In order to take variations in outdoor pollution levels into account, the homes were selected to be located in urban, suburban and rural areas (Fig. S1 in the Supplementary). According to Leipzig-Informationsystem (LIS) (Amt-fürStatistik-und-Wahlen, 2016) and Statistik-Berlin-Brandenburg (Amt-für-Statistik-Berlin-Brandenburg, 2015), the population density among the selected geographical area ranges from 60 to 14,000 person $\mathrm{km}^{-2}$. Half of the homes were located within 150 meters of the relatively busy roads, allowing us to assess the impact of differences in externally emitted traffic particles. All homes were typical German-style (solid brickwork), equipped with double-glazed windows and naturally ventilated (i.e., by opening a window or terrace/ balcony door), except for the homes L6, B4, B6, and B9 that were equipped with a mechanical ventilation system.

As to interior building design and occupation, the selected homes represent a variety of indoor environments - in terms of numbers of inhabitants, size of the living area, age of the inhabitants, and function (e.g., single apartment, family house). In wintertime, all homes were heated by a centralized heating system. Ten among them had the additional option to be heated by a closed fireplace (burning wood). Two of the homes were equipped with a gas cooking stove while all other homes were equipped with an electric cooking stove, which is very common nowadays in Germany. 16 of 40 homes were also occupied by children/teenagers. More details about the measurement homes are listed in Table S1 in the Supplementary.

The indoor aerosol sampling took place in the living room/dining room, in which people mainly spent their time. Outdoor aerosol sampling took place either on the balcony, terrace or in connected yard/garden. Both indoor and outdoor systems were with the inlet height at around 1.7 meters. 
Table 1. Characteristics of the residences under study in Leipzig and Berlin.

\begin{tabular}{|c|c|c|c|c|c|c|}
\hline \multirow{2}{*}{ Homes } & \multirow{2}{*}{ Location area } & \multirow{2}{*}{$\begin{array}{l}\text { Distance to the } \\
\text { next main road }(\mathrm{m})\end{array}$} & \multirow{2}{*}{$\begin{array}{l}\text { Residence } \\
\text { type }\end{array}$} & \multirow{2}{*}{$\begin{array}{l}\text { Number of } \\
\text { inhabitants }\end{array}$} & \multicolumn{2}{|c|}{ Season, days of measurement } \\
\hline & & & & & $1^{\text {st }}$ measurement & $2^{\text {nd }}$ measurement \\
\hline L1 & rural & $>150$ & House & 2 & cold, 3 & transition, 6 \\
\hline $\mathrm{L} 2$ & rural & $>150$ & house & $4-7$ & cold, 14 & transition, 11 \\
\hline L3 & rural & $>150$ & house & 4 & cold, 4 & transition, 8 \\
\hline L4 & rural & $>150$ & house & 3 & cold, 4 & transition, 7 \\
\hline L5 & rural & $>150$ & house & 2 & cold, 3 & warm, 6 \\
\hline L6 & rural & $50-150$ & house & 2 & cold, 4 & transition, 7 \\
\hline L7 & rural & $>150$ & house & 2 & cold, 3 & transition, 4 \\
\hline L8 & rural & $>150$ & house & 3 & transition, 3 & warm, 7 \\
\hline L9 & suburban & $10-50$ & house & 1 & cold, 3 & warm, 7 \\
\hline L10 & suburban & $10-50$ & house & 4 & transition, 3 & - \\
\hline L11 & urban & $>150$ & house & 3 & transition, 2 & warm, 7 \\
\hline L12 & suburban & $<10$ & apartment & 2 & cold, 4 & warm, 14 \\
\hline L13 & urban & $>150$ & apartment & 5 & cold, 4 & warm, 6 \\
\hline L14 & urban & $10-50$ & apartment & 4 & transition, 4 & warm, 7 \\
\hline L15 & urban & $50-150$ & apartment & 1 & transition, 3 & transition, 7 \\
\hline L16 & suburban & $10-50$ & apartment & 2 & transition, 4 & warm, 4 \\
\hline L17 & suburban & $<10$ & apartment & 1 & cold, 3 & transition, 7 \\
\hline L18 & urban & $10-50$ & apartment & 1 & transition, 6 & transition, 7 \\
\hline L19 & suburban & $50-150$ & apartment & 3 & cold, 4 & transition, 7 \\
\hline L20 & urban & $10-50$ & apartment & 3 & transition, 3 & warm, 2 \\
\hline B1 & rural & $>150$ & house & 1 & cold, 7 & transition, 7 \\
\hline B2 & rural & $50-150$ & house & 6 & cold, 7 & transition, 7 \\
\hline B3 & rural & $>150$ & house & 3 & cold, 7 & transition, 7 \\
\hline B4 & rural & $50-150$ & house & 2 & warm, 7 & cold, 7 \\
\hline B5 & rural & $>150$ & house & 2 & warm, 7 & cold, 7 \\
\hline B6 & rural & $>150$ & house & 3 & warm, 7 & cold, 7 \\
\hline B7 & suburban & $<10$ & house & 6 & cold, 7 & warm, 6 \\
\hline B8 & suburban & $10-50$ & house & 2 & cold, 7 & transition, 7 \\
\hline B9 & suburban & $>150$ & house & 4 & cold, 7 & warm, $8 ;$ transition, 8 \\
\hline B10 & suburban & $>150$ & house & 2 & cold, 7 & cold, 7 \\
\hline B11 & suburban & $>150$ & house & 4 & cold, 7 & warm, 7 \\
\hline B12 & urban & $>150$ & house & 2 & transition, 7 & cold, 7 \\
\hline B13 & suburban & $50-150$ & apartment & 5 & cold, 7 & transition, 7 \\
\hline B14 & suburban & $>150$ & apartment & 2 & warm, 7 & cold, 7 \\
\hline B15 & urban & $50-150$ & apartment & 4 & cold, 7 & transition, 7 \\
\hline B16 & urban & $50-150$ & apartment & 4 & warm, 7 & cold, 7 \\
\hline B17 & rural & $50-150$ & apartment & 2 & cold, 7 & transition, 5 \\
\hline B18 & urban & $<10$ & apartment & 3 & warm, 7 & cold, 7 \\
\hline B19 & urban & $50-150$ & apartment & 1 & warm, 7 & cold, 7 \\
\hline B20 & urban & $>150$ & apartment & 4 & warm, 7 & cold, 7 \\
\hline
\end{tabular}

\section{Instrumentation}

Indoor and outdoor measurements were performed simultaneously. To achieve the data most approximate the real-use conditions, the homes were not interrupted by measurement crews during the individual campaign periods; and thus, the measurement was followed up online.

The PNSD (Dp: 10-800 nm, time resolution of 5 minutes) was measured by TROPOS-designed mobility particle size spectrometers (MPSS) as described by Wiedensohler et al. (2012). $N_{F P}$ and $N_{U F P}$ were calculated by integrating the PNSD over the specified Dp range in 10-800 nm and 10 $100 \mathrm{~nm}$, respectively. In addition, the indoor setup also recorded the indoor temperature and relative humidity. $\mathrm{PM}_{10}, \mathrm{PM}_{2.5}$ mass concentrations were measured with 5- minute time resolution by optical particle size spectrometers (OPSS Grimm, Model 1.108). Furthermore, the indoor $\mathrm{CO}_{2}$ concentration was determined by a $\mathrm{CO}_{2}$ sensor (GMP252 Vaisala) with a one-minute time resolution, which was utilized to estimate the ventilation rate.

The indoor and outdoor OPSS were inter-compared in the laboratory regularly. The indoor and outdoor MPSS were routinely checked against reference instruments at the calibration center facilities at TROPOS. Quality assurance of indoor and outdoor systems are described in detail in the Supplementary, following the recommendations given in Wiedensohler et al. (2018).

During the measurements, the inhabitants were asked to mark their activities (e.g., open window, cooking, candle 
burning, and room cleaning) on a digital notebook. Therefore, the "activities log" with time-activity data could be accessed. The measurements were also accompanied by a questionnaire to document the room characteristics. Detailed information about the measurement procedure, instrument quality assurance, and residential activity categories used in this study are described in a previously published paper by Zhao et al. (2018).

\section{Data Analysis}

MPSS and OPSS data were measured as average concentrations in 5 minutes. The 5 -minute concentration data were used to analyze the temporal and seasonal variability of measured parameters, as well as to calculate the factors that affect the indoor and outdoor relationship. Hourly averaged concentrations were used to compute the summary statistics of different parameters. Statistical data analysis included arithmetic mean concentrations, standard deviations (SD), median, $25^{\text {th }}$, and $75^{\text {th }}$ percentile. Wilcoxon signed-rank test was carried out to analyze the relationship between indoor and outdoor particle concentrations (nonnormal distributed) using RStudio (R version 3.3.2, Package stats version 3.3.2). Without specific notes, the boxplot in this paper shows the median, $25^{\text {th }}$ and $75^{\text {th }}$ percentile, the whiskers are $5^{\text {th }}$ and $95^{\text {th }}$ percentile.

Due to the lower size detection limit of Grimm OPSS (approximately $0.3 \mu \mathrm{m}$ optical diameter), the PMC for submicrometer particles $\left(\mathrm{PM}_{1[\mathrm{OPSS}]}\right)$ might be generally underestimated. In this study, we used the PNSD to calculate the PMSD, and from this the $\mathrm{PM}_{1[\mathrm{PNSD}]}$ mass concentration. Assuming particle density is $1.5 \mathrm{~g} \mathrm{~cm}^{-3}$ (Pitz et al., 2003), the upper size limit of PNSD (around $800 \mathrm{~nm}$ mobility diameter) is approximately equal to $1 \mu \mathrm{m}$ aerodynamic diameter (assuming spherical particles). In this study, the $\mathrm{PM}_{1[\mathrm{OPSS}]}$ was on average $54 \%$ and $65 \%$ of the $\mathrm{PM}_{1[\mathrm{PNSD}]}$ mass concentration for indoor and outdoor, respectively.

Therefore, $\mathrm{PM}_{1[\mathrm{PNSD}]}$ is used to represent $\mathrm{PM}_{1}$ in the following sections. Additionally, the coarse mode PMC measured by the OPSS is reported as $\mathrm{PM}_{1-2.5}$ and $\mathrm{PM}_{2.5-10}$. The final $\mathrm{PM}_{2.5}$ and $\mathrm{PM}_{10}$ mass concentrations used here were thus determined by subtracting the $\mathrm{PM}_{1[\mathrm{OPSS}]}$ and adding the $\mathrm{PM}_{1[\mathrm{PNSD}]}$ mass concentrations. The calculations of these parameters are summarized below:

$$
\begin{aligned}
& \mathrm{PM}_{1}=\mathrm{PM}_{1[\mathrm{PNSD}]} \\
& \mathrm{PM}_{1-2.5}=\mathrm{PM}_{2.5[\mathrm{OPSS}]}-\mathrm{PM}_{1[\mathrm{OPSS}]} \\
& \mathrm{PM}_{2.5-10}=\mathrm{PM}_{10[\mathrm{OPSS}]}-\mathrm{PM}_{2.5[\mathrm{OPSS}]} \\
& \mathrm{PM}_{2.5}=\mathrm{PM}_{2.5[\mathrm{OPSS}]}-\mathrm{PM}_{1[\mathrm{OPSS}]}+\mathrm{PM}_{1[\mathrm{PNSD}]} \\
& \mathrm{PM}_{10}=\mathrm{PM}_{10[\mathrm{OPSS}]}-\mathrm{PM}_{1[\mathrm{OPSS}]}+\mathrm{PM}_{1[\mathrm{PNSD}]}
\end{aligned}
$$

The indoor-to-outdoor $(\mathrm{I} / \mathrm{O})$ ratio as a commonly used quantity for the indoor-to-outdoor relationship was also investigated. It is also an indicator of aerosol sources with indoor or outdoor origin. The I/O ratio was calculated by dividing the indoor particle number/mass concentration to those from outdoors.

\section{Ventilation Rates}

Temperature data was analyzed to capture the actual season of the year (see Supplementary, Fig. S7), the definition of the cold, transition, and warm seasons is discussed in the Supplementary. The ventilation rates $(\lambda)$ can be estimated by the decay method of passive trace gas such as $\mathrm{CO}_{2}$ (Mahyuddin and Awbi, 2012; Alves et al., 2013; Turanjanin et al., 2014). When people stay indoors, $\mathrm{CO}_{2}$ concentration increases from exhalation. Considering that residents stay at least overnight indoor, indoor $\mathrm{CO}_{2}$ accumulates and the concentration exceeds outdoors over a certain period. At time $t_{0}$ when people have left the house, i.e., there is no more $\mathrm{CO}_{2}$ source, indoor $\mathrm{CO}_{2}$ concentration starts to decrease due to ventilation. With the assumption that indoor air was well mixed, Eq. (1) yields the ventilation rate as

$$
\lambda=\frac{1}{\left(t-t_{0}\right)} \ln \left(\frac{C_{0}-\mathrm{C}_{\text {out }}}{C-C_{\text {out }}}\right)
$$

where $C_{0}$ is the indoor $\mathrm{CO}_{2}$ concentration at time $t_{0}$, and correspondingly, $C$ is the indoor $\mathrm{CO}_{2}$ concentration at time t. $C_{\text {out }}$ is the outdoor $\mathrm{CO}_{2}$ concentration, which was assumed to be constant around $400 \mathrm{ppm}$, which is the current background $\mathrm{CO}_{2}$ concentration in ambient air. The sensitivity of the ventilation rate to the seasonal variation of background $\mathrm{CO}_{2}$ level is negligible (see Supplementary, Section 1.5).

The mean ventilation rate of the entire measurement period was $0.2 \pm 0.2 \mathrm{~h}^{-1}$ and $3.7 \pm 2.8 \mathrm{~h}^{-1}$ with closed and opened windows (at least one window is opened), respectively (see Table 2). In this paper, we define the periods with closed windows that are under a low ventilation condition. The frequency of the "open window" activity was twice per day on all-seasonal average. While the mean duration of "open window" in the cold and two transition seasons was less than one hour, it was almost seven times more in the warm season. Under warm outdoor temperatures, occupants tend to leave windows open for longer periods while at temperatures around or below about $10^{\circ} \mathrm{C}$ in the cold and transition seasons, they leave the windows closed most of the time.

\section{Material Balance Model}

The high time and size resolution of the PNSD measurements allows us to examine aerosol dynamic processes quantitatively. In the section Particle Infiltration and Loss, the PNSD data ( 71 bins in origin) measured by the MPSS were integrated as seven particle size fractions (in mobility diameter): $10-20,20-30,30-50,50-100,100-200$, 200-500, 500-800 $\mathrm{nm}$. These size ranges were chosen so that the large PNSD data set could be summarized for UFP (four size ranges from 10 to $100 \mathrm{~nm}$ ) and accumulationmode particles (three size ranges from 100 to $800 \mathrm{~nm}$ ), and at the same time, that the variation trend of PNSD could still be observed.

To determine the contribution of outdoor particles to indoor particle concentrations (indoor-to-outdoor relationship), the periods influenced by indoor sources have to be excluded. For all subsequent calculations, data are selected, which can be described as "steady state" periods. Note that if indoor $\mathrm{N}_{\mathrm{FP}}$ is lower than $10^{4} \mathrm{~cm}^{-3}$, particle coagulation can 
Table 2. Ventilation rate and ventilation frequency in three seasons.

\begin{tabular}{lllll}
\hline Season & $\begin{array}{l}\text { Mean Ventilation rate } \\
\text { - closed window }\left[\mathrm{h}^{-1}\right]\end{array}$ & $\begin{array}{l}\text { Mean Ventilation rate } \\
\text { - opened window }\left[\mathrm{h}^{-1}\right]\end{array}$ & $\begin{array}{l}\text { Mean frequency } \\
\text { of "open window" } \\
\text { [times/day] }\end{array}$ & $\begin{array}{l}\text { Mean duration } \\
\text { of "open window" } \\
\text { [hours] }\end{array}$ \\
\hline Cold season & $0.2 \pm 0.1$ & $4.1 \pm 3.2$ & 2 & 0.3 \\
Transition season & $0.2 \pm 0.1$ & $3.7 \pm 2.8$ & 2 & 0.6 \\
Warm season & $0.3 \pm 0.3$ & $3.1 \pm 2.0$ & 3 & 28.9 \\
Total & $0.2 \pm 0.2$ & $3.7 \pm 2.8$ & 3 & 1.6 \\
\hline
\end{tabular}

be neglected (Hussein et al., 2009a; Rim et al., 2012). Such periods require the absence of indoor activities (reported and/or observed from indoor particle data). Under these circumstances, the indoor-outdoor relationship of fine aerosol particles will be affected mainly by three mechanisms: indoor-outdoor ventilation, infiltration from outdoors, and particle deposition onto indoor surfaces. Assuming the indoor air was well mixed and certain particle size fractions have similar physical properties, the balanced equation of PNC describes the dynamic behavior of indoor aerosols. It is mathematically written in the form (Hussein and Kulmala, 2008; Bhangar et al., 2011):

$\frac{d I}{d t}=P \lambda O-\left(\lambda+\lambda_{d}\right) I$

where $I$ and $O$ are the $\mathrm{N}_{\mathrm{FP}}$ of indoor and outdoor air, respectively. Correspondingly, $\mathrm{dI} / \mathrm{dt}$ is the indoor $\mathrm{N}_{\mathrm{FP}}$ change rate. Here, $\lambda$ the ventilation rate, which has been calculated earlier, $\lambda_{d}$ the deposition and diffusion rate of particles onto available indoor surfaces (e.g., walls, furniture, floor), $\left(\lambda+\lambda_{d}\right)$ the total particle loss indoors, and $P$ the penetration factor.

Under ideal "steady state" conditions, the derivative of indoor $\mathrm{N}_{\mathrm{FP}}$ over time $(\mathrm{dI} / \mathrm{dt})$ approaches zero, therefore $P$ can be calculated from Eq. (2):

$P=\frac{\left(\lambda+\lambda_{d}\right) I}{\lambda O}$

Due to the fact that the measurements were at fixed spots, $P$ is not only describing the infiltration through building cracks, but also includes the effect from airways passing other rooms of the home. Particles are transported from outside into the home and reach the living room (measurement room). The penetration factor represents the size-resolved efficiency of this transport.

\section{RESULTS AND DISCUSSION}

\section{Overall Indoor and Outdoor Particle Concentrations}

Indoor and outdoor particle mass and number concentrations, as well as $\mathrm{CO}_{2}$ concentrations, were measured for around 8500 to 11500 hours in total. Numerical measurement statistics are overviewed in Table 3. and shown graphically in Fig. 1. The overall mean indoor and outdoor $\mathrm{PM}_{10}$ are $25 \mu \mathrm{g} \mathrm{m}^{-3}$ and $18 \mu \mathrm{g} \mathrm{m}^{-3}$, respectively, which is comparable to the mean concentrations in Birmingham (around $26 \mu \mathrm{g} \mathrm{m}^{-3}$ for indoor and $20 \mu \mathrm{g} \mathrm{m}^{-3}$ for outdoor) reported by
Jones et al. (2000), and much lower than in Portugal (around $71 \mu \mathrm{g} \mathrm{m}^{-3}$ for indoor and $54 \mu \mathrm{g} \mathrm{m}^{-3}$ for outdoor) reported by Custódio et al. (2014). Our $\mathrm{PM}_{2.5}$ concentration was also comparable to the concentrations (median values around $10 \mu \mathrm{g} \mathrm{m}^{-3}$ for both indoor and outdoor) reported in two studies in Sweden by Molnár et al. (2005, 2007).

The median indoor coarse particle number concentration was roughly two times as the outdoors. It is interesting to notice that, the median values of indoor $\mathrm{PM}_{2.5-10}$ mass concentrations were significantly higher than those outdoors (3.9 and $1.1 \mu \mathrm{g} \mathrm{m}^{-3}$, respectively; p-value $<<0.05$ ). The $\mathrm{PM}_{2.5-10}$ mass concentrations showed similar trends inside 32 homes out of 40 (see Fig. 2, the missing $5^{\text {th }}$ percentile whiskers in the boxplot of $\mathrm{PM}_{2.5-10}$ mass concentrations are because of the corresponding concentrations lower than $0.1 \mu \mathrm{g} \mathrm{m}^{-3}$.). However, the median indoor and outdoor $\mathrm{PM}_{1-2.5}$ mass concentration and its variability were rather similar (overall median values are 1.4 and $1.5 \mathrm{\mu g} \mathrm{m}^{-3}$, respectively; $\mathrm{p}$-value $=0.053$ ). In twelve of the homes, the indoor $\mathrm{PM}_{1-2.5}$ mass concentrations were significantly higher than those outdoors (see Fig. 2). The median I/O ratio of the $\mathrm{PM}_{2.5-10}$ and $\mathrm{PM}_{1-2.5}$ mass concentration were 2.75 and 1 , respectively. Indoors, the $\mathrm{PM}_{1-2.5}$ was significantly lower than $\mathrm{PM}_{2.5-10}$ mass concentration, indicating the reduced contribution of indoor dust sources to this size range.

For submicrometer particles, the overall median PNC outdoors was higher than those indoors (see Table 3.). This contrasts with the results of the overview study of Morawska et al. (2017). This is due to indoor sources' instantaneous strong contribution to the indoor PNC. To better represent the most common state in these homes median indoor and outdoor PNC was used.

The difference between the $1^{\text {st }}$ and $99^{\text {th }}$ percentile of the indoor PNC was around one order of magnitude higher than that outdoors (see boxplots' whiskers in Fig. 1); although this was not observed for $\mathrm{PM}_{1}$. The indoor and outdoor $\mathrm{N}_{\mathrm{FP}}$ by each home show similar trends in 33 of 40 homes (see Fig. 2). $\mathrm{N}_{\text {UFP }}$ is on average $83 \%$ and $82 \%$ of $\mathrm{N}_{\mathrm{FP}}$ for indoors and outdoors, respectively. This indicates that UFP makes up the majority of the number population of particles indoors and outdoors.

\section{Seasonal Variation \\ Diurnal Cycles of Particle Mass and Number Concentrations}

During the residents' active time (06:00-24:00), there is was a strong variation in the diurnal cycle of indoor coarse PMC ( $\mathrm{PM}_{2.5-10}$ and $\left.\mathrm{PM}_{1-2.5}\right)$ in the cold season (Fig. 3). While during night time, indoor coarse PMC decreased significantly 
Table 3. Hourly average statistics of indoor and outdoor particle concentrations, and $\mathrm{CO}_{2}$ concentration data for all measurements.

\begin{tabular}{|c|c|c|c|c|c|c|c|c|c|}
\hline \multirow{2}{*}{ Parameter } & \multirow{2}{*}{$\mathrm{N}\left(\right.$ hour) ${ }^{\mathrm{a}}$} & \multirow{2}{*}{ Mean } & \multirow{2}{*}{ SD } & \multirow{2}{*}{$\begin{array}{l}\text { Median } \\
\text { I/O ratio }\end{array}$} & \multicolumn{5}{|c|}{ Percentile } \\
\hline & & & & & Min & 0.25 & 0.50 & 0.75 & Max \\
\hline Indoor $\mathrm{PM}_{10}\left[\mu \mathrm{g} \mathrm{m}^{-3}\right]$ & 8969 & 25.31 & 41.28 & 0.99 & 0.80 & 8.68 & 16.13 & 28.97 & 1474.99 \\
\hline Outdoor $\mathrm{PM}_{10}\left[\mu \mathrm{g} \mathrm{m}^{-3}\right]$ & 8510 & 18.05 & 16.06 & & 0.82 & 8.61 & 13.7 & 22.28 & 418.92 \\
\hline Indoor $\mathrm{PM}_{2.5}\left[\mu \mathrm{g} \mathrm{m}^{-3}\right]$ & 8969 & 13.47 & 26.57 & 0.76 & 0.7 & 5.52 & 9.3 & 14.83 & 1278.74 \\
\hline Outdoor $\mathrm{PM}_{2.5}\left[\mu \mathrm{g} \mathrm{m}^{-3}\right]$ & 8510 & 16.06 & 15.13 & & 0.64 & 6.96 & 11.45 & 20.16 & 418.31 \\
\hline Indoor $\mathrm{PM}_{1}\left[\mu \mathrm{g} \mathrm{m}^{-3}\right]$ & 10564 & 10.44 & 27.97 & 0.69 & 0.35 & 3.91 & 6.99 & 11.73 & 2174.79 \\
\hline Outdoor $\mathrm{PM}_{1}\left[\mu \mathrm{g} \mathrm{m}^{-3}\right]$ & 11296 & 13.41 & 13.07 & & 0.47 & 5.08 & 9.79 & 17.78 & 415.53 \\
\hline Indoor $\mathrm{N}_{\mathrm{FP}}\left[\mathrm{cm}^{-3}\right]$ & 10564 & 9498 & 24002 & 0.69 & 680 & 2386 & 4108 & 7553 & 649264 \\
\hline Outdoor $\mathrm{N}_{\mathrm{FP}}\left[\mathrm{cm}^{-3}\right]$ & 11296 & 7219 & 5762 & & 1480 & 3789 & 6015 & 8909 & 177777 \\
\hline Indoor $\mathrm{N}_{\mathrm{UFP}}\left[\mathrm{cm}^{-3}\right]$ & 10564 & 8634 & 23326 & 0.65 & 506 & 1823 & 3378 & 6654 & 641983 \\
\hline Outdoor $N_{\text {UFP }}\left[\mathrm{cm}^{-3}\right]$ & 11296 & 6203 & 5474 & & 1096 & 3069 & 4928 & 7619 & 176643 \\
\hline Indoor $\mathrm{CO}_{2}[\mathrm{ppm}]$ & 11024 & 749 & 285 & 1 & 385 & 547 & 671 & 863 & 2853 \\
\hline
\end{tabular}

${ }^{\text {a }}$ Measurement data were collected every five minutes, the table here shows the statistics of hourly average concentration.

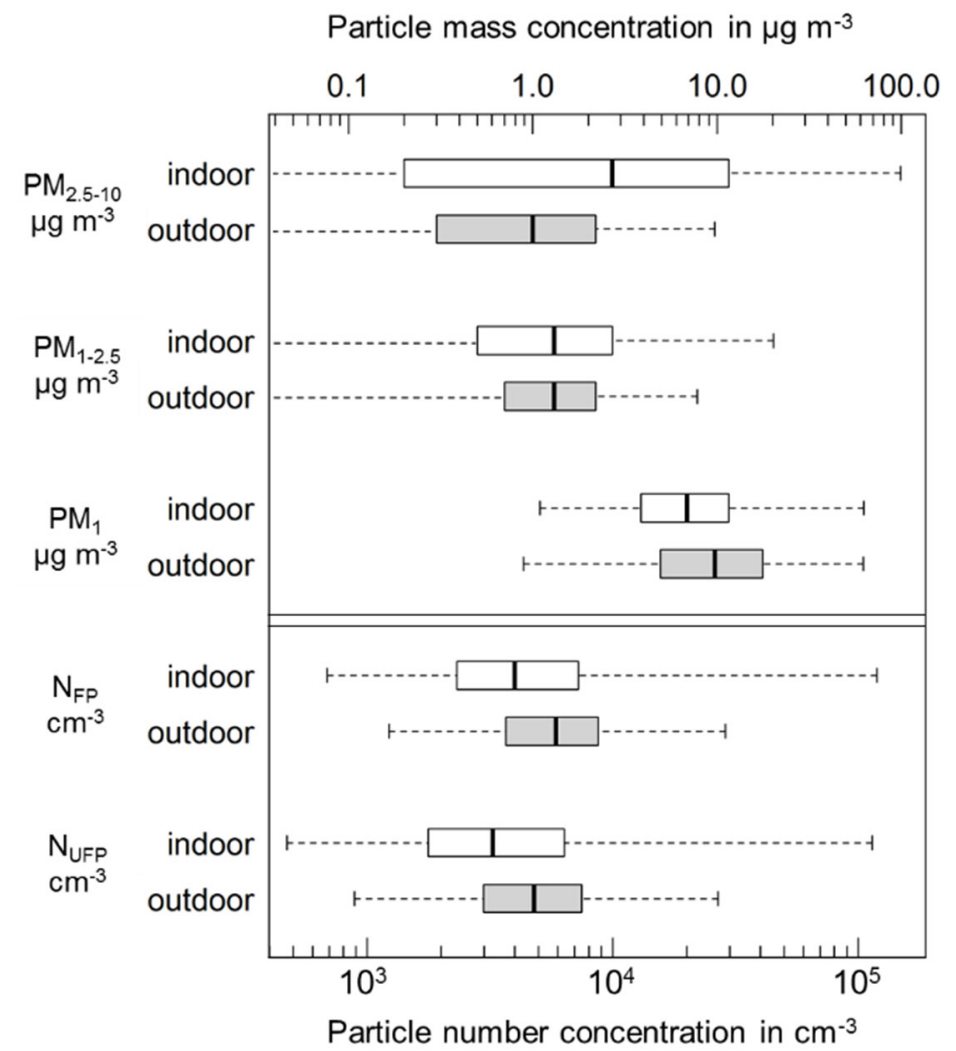

Fig. 1. Overall statistics of $\mathrm{PM}_{2.5-10}, \mathrm{PM}_{1-2.5}$, and $\mathrm{PM}_{1}$ mass concentrations, $\mathrm{N}_{\mathrm{FP}}$ and $\mathrm{N}_{\mathrm{UFP}}$. Whiskers are $1^{\text {st }}$ and $99^{\text {th }}$ percentile.

so that they become gradually lower than the corresponding outdoors, and eventually reach a value close to zero. This indicated the strong contribution of user activities in the home, which causes emission or resuspension of particles (e.g., by cooking, walking, and sweeping the floor). The effect was more pronounced for $\mathrm{PM}_{2.5-10}$ than for $\mathrm{PM}_{1-2.5}$. During the period when people are asleep, indoor coarse PMC was decreasing due to sedimentation, and the infiltration was not significant.

The PMC of $\mathrm{PM}_{2.5-10}, \mathrm{PM}_{1-2.5}$ and $\mathrm{PM}_{1}$ showed similar trends in the cold and warm season. Nevertheless, in warm season $\mathrm{PM}_{2.5-10}$ was lower and shows stronger decreasing during the active time than in cold season. One reason is the enhanced ventilation during the warm season. On the other hand, indoor heating not only increases the air turbulence but also decreases the indoor relative humidity during the cold season (see Fig. S10 in Supplementary), leading to longer particle lifetimes caused by re-suspension. In both cold season and warm season, there is a significant delineation between indoor and outdoor coarse PMC, especially in the 2.5-10 $\mu \mathrm{m}$ particle range. In order to obtain correct exposure measures, indoor PMC measurements for coarse particles will be required.

For submicrometer particles, in the cold season, the trends 
Particle mass concentration

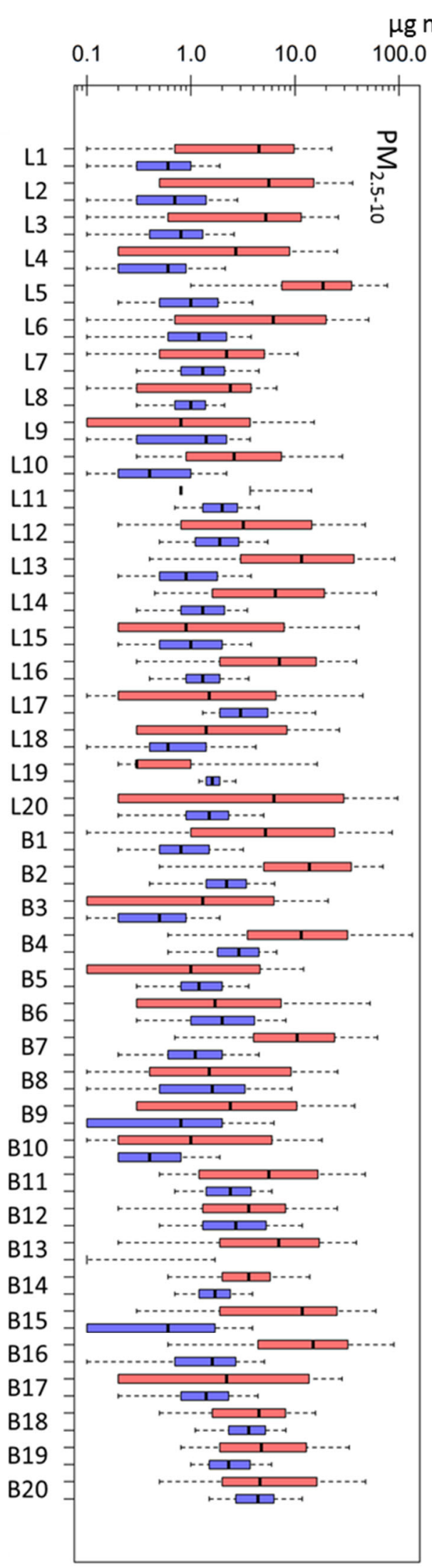

Particle number concentration

$\mathrm{cm}^{-3}$

$1 \mathrm{e}+03 \quad 1 \mathrm{e}+04 \quad 1 \mathrm{e}+05$
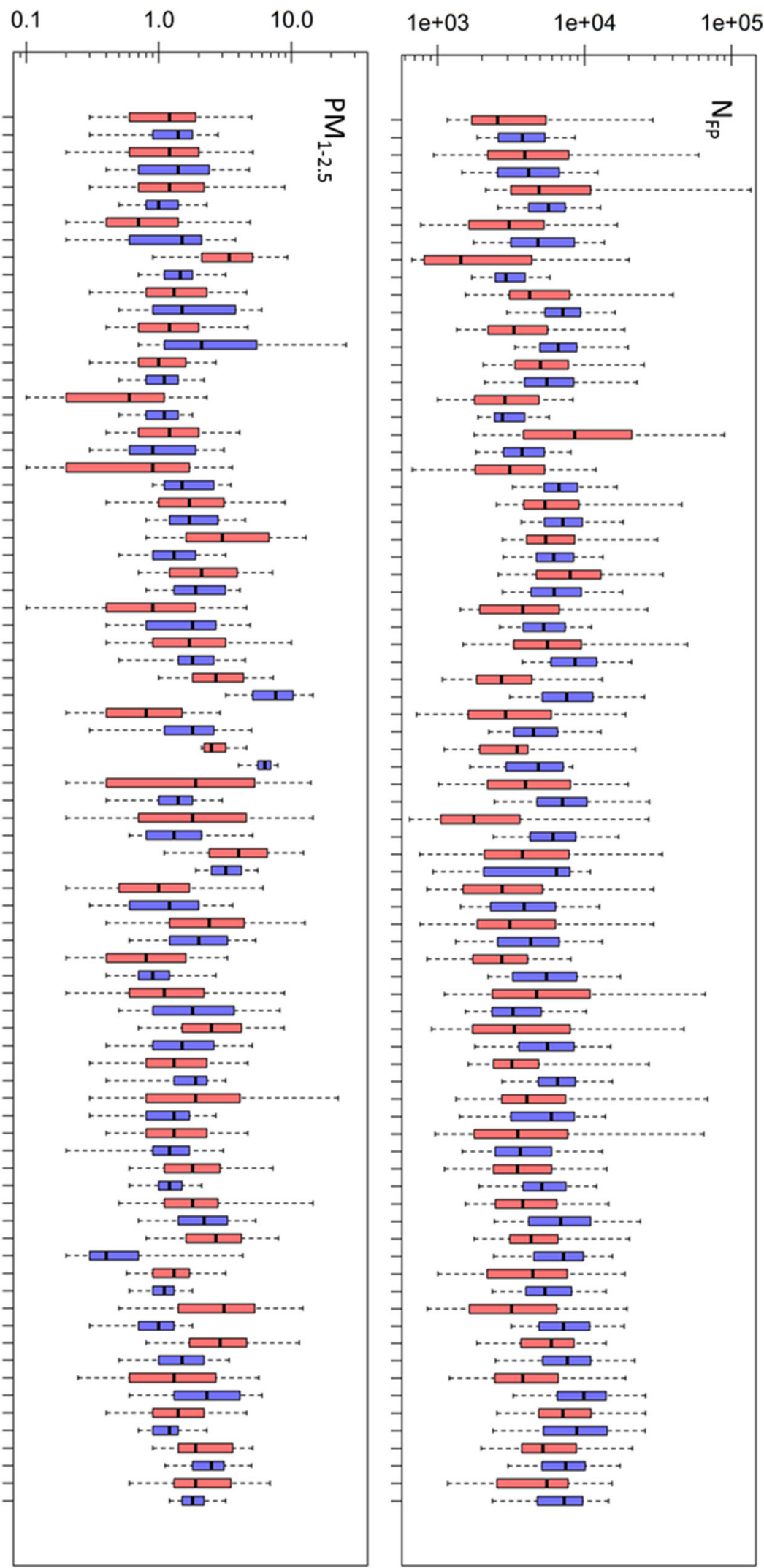

[ indoor a outdor

Fig. 2. Indoor and outdoor $\mathrm{PM}_{2.5-10}$ and $\mathrm{PM}_{1-2.5}$ mass concentrations, $\mathrm{N}_{\mathrm{FP}}$ by each home. 


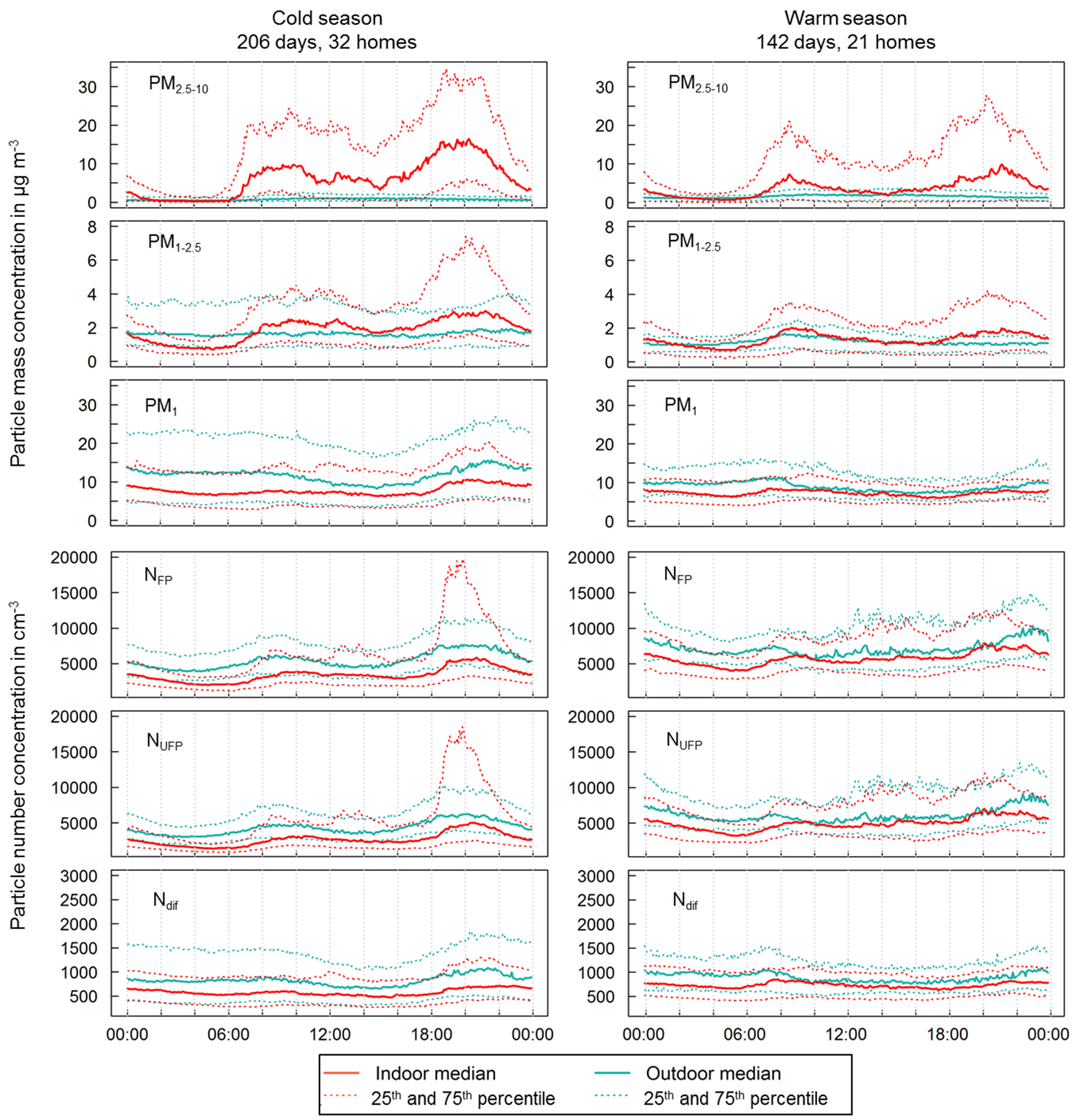

Fig. 3. Diurnal cycle of the indoor and outdoor $\mathrm{PM}_{2.5-10}, \mathrm{PM}_{1-2.5}, \mathrm{PM}_{1}, \mathrm{~N}_{\mathrm{FP}}, \mathrm{N}_{\mathrm{UFP}}$ and $\mathrm{N}_{\text {dif }}$ in the cold and warm seasons.

of $\mathrm{N}_{\mathrm{FP}}$ and $\mathrm{N}_{\mathrm{UFP}}$ in the diurnal cycle are very similar, the $75^{\text {th }}$ percentile of indoor PNC shows strong peaks however around 8:00, 12:00 and 19:00, which are the typical times of breakfast, lunch, and dinner, two of them (around 12:00 and 19:00) even exceeded outdoors. The peak time of indoor activities' frequency was matching the $75^{\text {th }}$ percentile of indoor PNC (see Fig. S11 in the Supplementary). However, the diurnal cycle of accumulation mode particles (i.e., $\mathrm{N}_{\text {dif }}$, the differences between $\mathrm{N}_{\mathrm{FP}}$ and $\mathrm{N}_{\mathrm{UFP}}$, see Fig. 3) was very stable, was neither significant sinking during the night time, nor notable increasing during the active time. Median PNSDs during four frequent indoor activities (toasting, baking, frying, and burning candle) and opening windows are illustrated in Fig. S12 in the Supplementary. Results showed a significant contribution from indoor cooking activities, moreover, the contribution to UFP was much more compared with accumulation mode particles. This indicated that ultrafine particles not only make up the majority of the number population of indoor fine particles, but also potentially dominate the variation of indoor PNC caused by indoor sources in the cold season.

Indoor $\mathrm{N}_{\mathrm{FP}}$ and $\mathrm{N}_{\mathrm{UFP}}$ in warm seasons show less significant peaks than in the cold season. This reflects the influence of ventilation. In cold and transition seasons, there were shorter ventilation durations, meaning that particles produced indoors remain longer inside. On the other hand, due to the 
longer duration of enhanced ventilation in the warm season, the indoor air was more frequently mixed with air from outside. Therefore, the indoor $\mathrm{N}_{\mathrm{FP}}, \mathrm{N}_{\mathrm{UFP}}$, and $\mathrm{N}_{\mathrm{dif}}$ in the warm season were more stable and closer to the outdoor concentrations, however, generally still lower. In the warm season, outdoor sources dominated the variation of the diurnal cycle of indoor submicrometer particles.

Transition seasons are not discussed independently for the seasonal variation, because of the ventilation rates, frequency, as well as the behavior of diurnal cycles in the transition season were between cold season and warm season. (Diurnal cycles in transition season are in the Supplementary, Fig. S9).

\section{Particle Number and Mass Size Distributions}

Outdoor median PMC and PNC for the entire size range were all higher than indoors (Fig. 4). In the cold season, the
PNSD
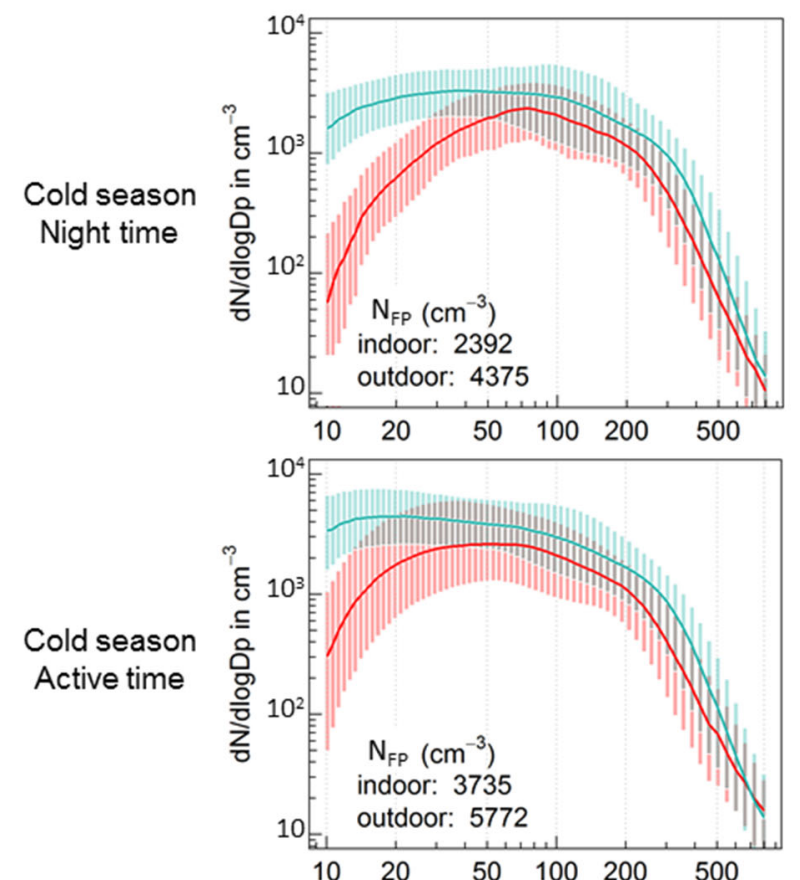

Cold season Active time

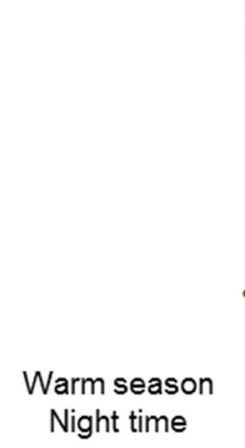

Activeason Active time
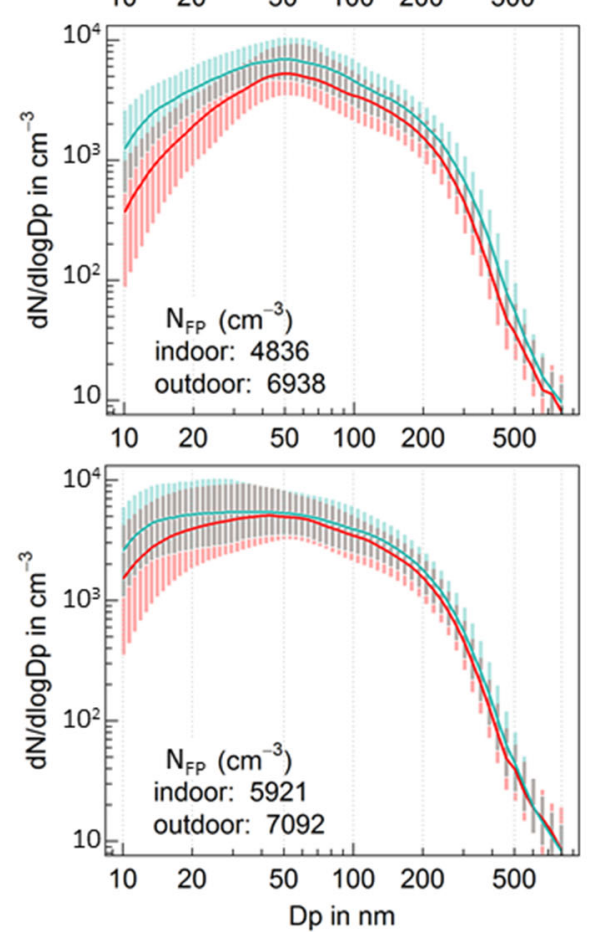

PMSD
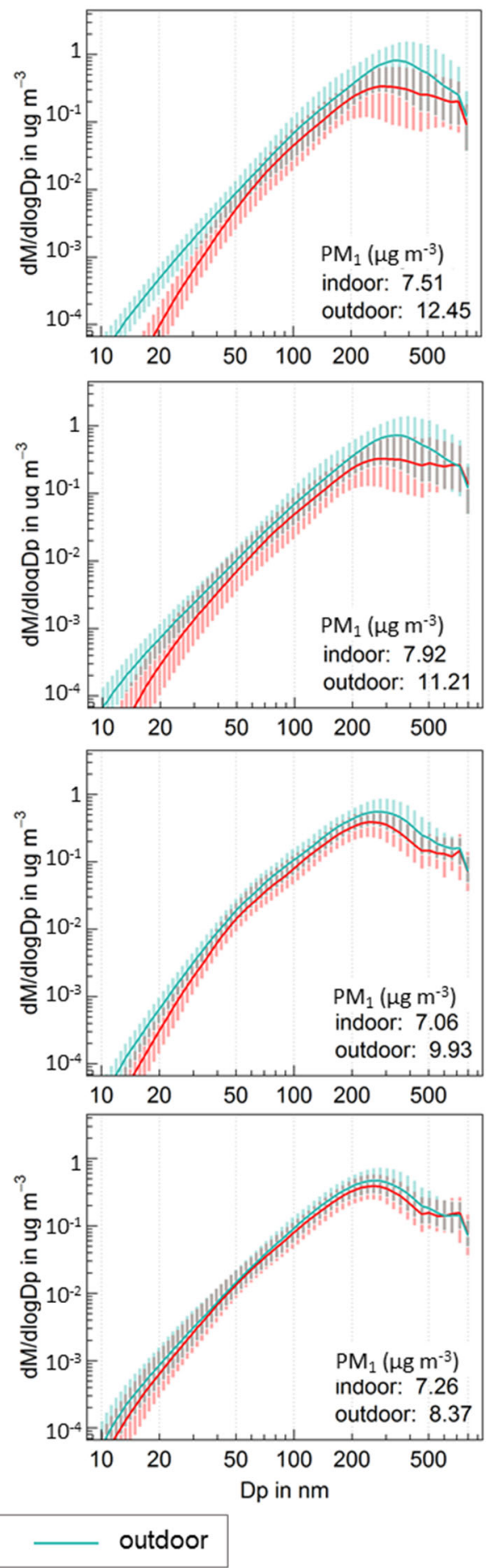

Fig. 4. Boxplots of PNSDs and PMSDs during night time and active time in the cold and warm seasons. 
indoor PNC was much lower, and the indoor PNSD showed different patterns as outdoors - with much lower UFP concentrations. While in the warm season, the indoor and outdoor PNSD patterns were very similar, especially during the active time, due to the longer periods of ventilation using the windows. The indoor median $\mathrm{N}_{\mathrm{FP}}$ in the active time was 1.6 and 1.2 times as high as during night time for the cold and warm season, respectively. Indoors, the increase of median PNC for 10-100 nm size range was notably higher than for 100-800 nm (106.3 and 43.6 times as high as in cold and warm seasons, respectively). This emphasizes the strong contribution of indoor sources to UFP. Overall, in the cold season, indoor particles' composition is much different compared to outdoors.

Similar seasonal variation trends as in PNSD can be observed in the PMSD. However, the indoor and outdoor $\mathrm{N}_{\mathrm{FP}}$ in the cold season were lower than those in the warm season, while the indoor and outdoor $\mathrm{PM}_{1}$ in the cold season were higher than those in the warm season. This indicates that there were more accumulation mode particles in the cold season than in the warm season, an effect which is linked to the annual cycle of outdoor concentrations in the East German region (Sun et al., 2019).

The median outdoor particle concentrations exceeded those indoors at all times of day, for all size ranges, regardless of season, suggesting that outdoor infiltration increased the indoor PNC of the submicron particle. Therefore, the sizeresolved efficiency of this process is evaluated and discussed in the following sections.

\section{Particle Infiltration and Loss}

I/O Ratio in "Steady State" Periods

$\mathrm{dI} / \mathrm{dt}$ has been calculated for the entire measurements (dataset in 5 minutes resolution). A positive value of $\mathrm{dI} / \mathrm{dt}$ means indoor PNCs increase and vice versa. The $25^{\text {th }}$, median and $75^{\text {th }}$ percentile of the $\mathrm{dI} / \mathrm{dt}$ is around $-0.45,-0.11$ and $0.02\left(\mathrm{~cm}^{-3} \mathrm{~s}^{-1}\right)$, respectively. A large fraction of the $\mathrm{dI} / \mathrm{dt}$ values is below zero, indicating that the gradual decline of PNC is a frequent condition of indoor air. The threshold of the steady state was chosen between -0.1 and 0.1 , and a steady duration should be longer than one hour. As a result, around 800 measurement hours' data satisfied the condition.

Fig. 5 shows the boxplot of the size-resolved I/O ratio under the steady state conditions. The median $\mathrm{I} / \mathrm{O}$ ratio shows the maximum at $100-200 \mathrm{~nm}$ and the minimum at 10-20 nm. The median of the I/O ratio for each size range varied from 0.10 to 0.58 , providing evidence that outdoor sources are the main contributor to indoor $\mathrm{N}_{\mathrm{FP}}$.

\section{Indoor Particle Loss Rate}

The indoor particle loss rate $\left(\lambda+\lambda_{d}\right)$ was quantified by tracking the decay of the indoor PNC right after being emitted/re-suspended during an indoor activity under low ventilation conditions. The particle loss rate is the negative slope in the logarithm of indoor $\mathrm{N}_{\mathrm{FP}}$ as a function of time. The indoor particle loss rate of the 40 homes as a function of the particle size is shown in Fig. 6. Despite the large variation, the minimum particle loss is as expected in the accumulation mode range (Dp: $100-300 \mathrm{~nm}$ ) and the median

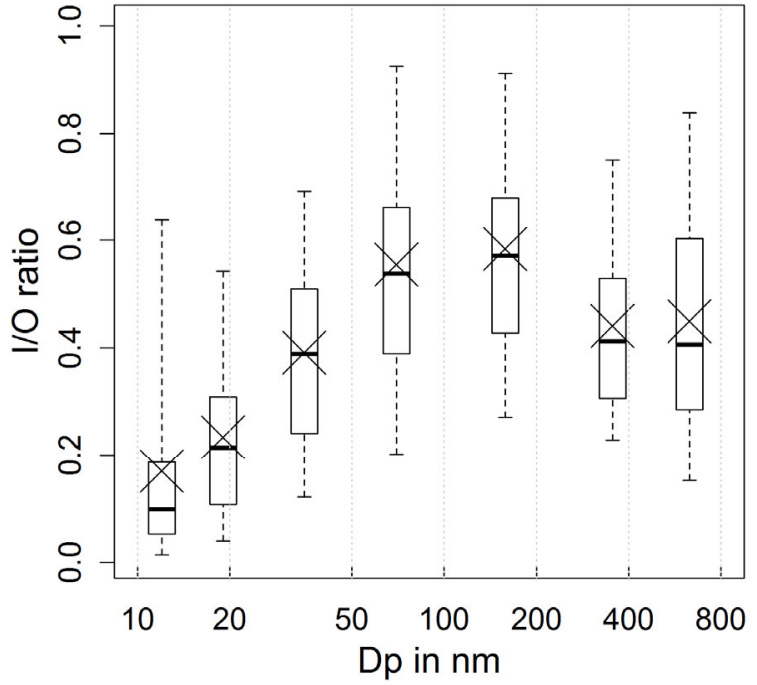

Fig. 5. Size-resolved I/O ratio under steady state conditions. $\times$ marks the mean value.

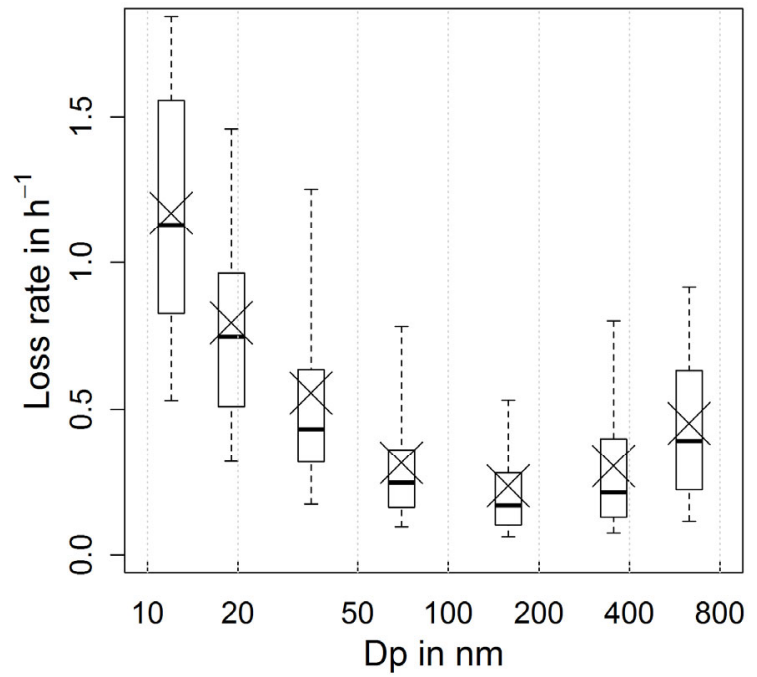

Fig. 6. Size-resolved indoor particle loss rate $\left(\lambda+\lambda_{d}\right)$. $\times$ marks the mean value.

particle loss rate in this size range was around $0.2 \mathrm{~h}^{-1}$. Indoor particle losses are particularly effective in reducing ultrafine PNC, and maximum particle losses are around 10-20 nm with a median loss rate of around $1.1 \mathrm{~h}^{-1}$. In the $10-20 \mathrm{~nm}$ size range, particle losses are mainly caused by diffusion to any surface in the room. This explains the lower UFP concentrations during the cold season, when most of the time was under the low ventilation condition.

The indoor particle deposition strongly depends on the area, configuration, and material of the indoor surfaces, as well as the room volume (Long et al., 2001). Each home thus has its specific $\lambda_{d}$ (assuming there is no sudden temperature change or ventilation). Therefore, the $\left(\lambda+\lambda_{d}\right)$ values are used to estimate the penetration factor of corresponding homes.

\section{Particle Penetration Factor}

Particle penetration factors for the building shells were 
calculated using Eq. (3). The result is shown as boxplot (red) in Fig. 7. No certain trend was from the aspects of layouts or dimensions of the measuring sites. The reason could be that there are 40 samples under these aspects, after the division into groups the number of samples is probably not sufficient to obtain clear trends. In general, the median penetration factors were relatively low (not exceeding 0.5 for any size range), indicating the low infiltration, which reflects that German homes are relatively airtight and allow for particles penetrating with low efficient from outdoors only. Together with the indoor particle losses, leading to the much lower indoor PNC in the cold season.

The average penetration factor curve by Long et al. (2001) lies between the $75^{\text {th }}$ and $95^{\text {th }}$ percentile of this study - the older sampling homes in their study (e.g., one is more than 300 years old) could explain this result. Measurements of Zhao and Stephens (2017) and Hussein et al. (2005) were carried out in a rather airtight modern suite in Chicago and in one house in Finland, respectively. As a result, the penetration curves in these two studies lie between the $25^{\text {th }}$ and $95^{\text {th }}$ percentile of this study, indicating these two homes have similar tightness comparing with our homes.

The median penetration factors show a maximum of 0.5 for around $50 \mathrm{~nm}$ diameter particles, i.e. particles with such a diameter will penetrate a building shell most easily. The penetration factors increase with the particle size from 10 to $50 \mathrm{~nm}$. Similar behaviors were observed by Long et al. (2001), Zhao and Stephens (2017) and Hussein et al. (2005). However, the behaviors of penetrations factors in 100-500 nm size range estimated by Long et al. (2001) and Hussein et al. (2005) were different from this study. T. Hussein 2005 applied the model from Liu and Nazaroff (2001) to estimate the penetration factor across the building shell, the model is under an assumption of a certain crack structure for one house. Therefore, pure modeled results and a single measurement site could be the reason for the different trends from this study. The uncertainty of the penetration factor caused by measurements is negligible (see Supplementary). There is one concern related to the quantification of particle loss rate. The quantification was done under the assumption of a criterion for the negligence of coagulation using the specific total particle number concentration of $\sim 1.0 \times 10^{4} \mathrm{~cm}^{-3}$ (Hussein et al., 2009a). However, in real-life conditions, right after indoor sources there could still be coagulation, due to the inhabitant's influence and complex chemical composition. This would lead to an underestimation of particle losses in accumulation mode $(100-500 \mathrm{~nm})$, the penetration factor would then also be underestimated for this size range.

\section{SUMMARY AND CONCLUSION}

A novel dataset including parallel indoor and outdoor $\mathrm{PM}_{10}$, $\mathrm{PM}_{2.5}$ and PNSD were collected in 40 homes in Leipzig and Berlin under real-use conditions, covering a wide variety of residential indoor environments - from $40 \mathrm{~m}^{2}$ single apartment to $220 \mathrm{~m}^{2}$ detached family house. The over 500 days' measurements, allow us to obtain better representative diurnal and seasonal variation pattern of indoor exposure to coarse, fine and ultrafine particles in Europe, and analyzed the corresponding indoor-to-outdoor relationships. In the next step, we quantified and analyzed the processes that influence the indoor PNSD, including size-resolved indoor particle loss rates, and building shell penetration factors from a steady state approximation.

Mass concentrations of coarse mode particle, especially $\mathrm{PM}_{2.5-10}$, were linked to resuspension processes driven by residents' activities, showed significantly higher concentrations and greater variability than outdoors, indicating that indoor activities were the major contributors to indoor coarse particles. Clearly, in German residential environments, indoor

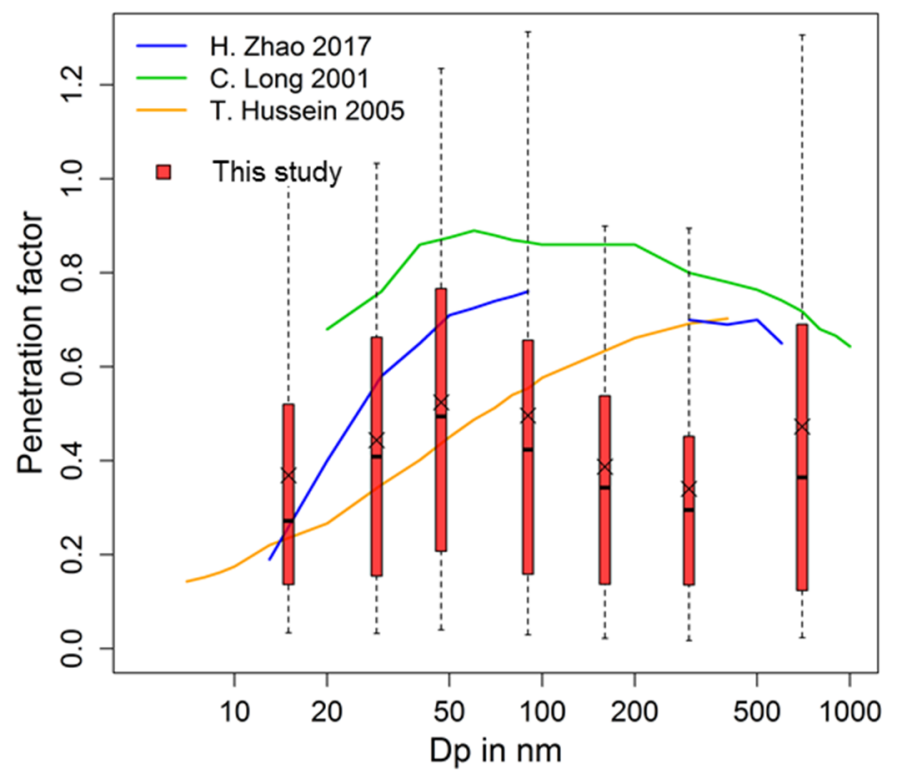

Fig. 7. Size-resolved penetration factor of 40 homes in this study (red boxplot), $\times$ marks the mean value of this study. In comparison, there are penetration factor curves estimated by Zhao and Stephens (2017), Long et al. (2011), and Hussein et al. (2005). 
exposure to coarse particles cannot be described by outdoor measurements.

For submicrometer particles, the median indoor $\mathrm{PM}_{1}$ and $\mathrm{N}_{\mathrm{FP}}$ diurnal cycles were lower than those outdoors (median I/O ratio both 0.69), and following outdoors' variation. Overall, the variation of median indoor submicrometer particles was driven by outdoor sources primarily. This result is contrary to the conclusion in the review study of Morawska et al. (2017), which concluded that indoor sources are the main drivers of home PNC. One reason is that in this study the median value was used to compare indoor and outdoor PNC instead of the mean, to represent the most common state of those 500 days' measurement. Another reason is that, the review study covers the residents' activity habits in many different countries. This also highlights the importance of residential measurement in the region of central Europe, where the housing situation is different from other areas of the world.

Ultrafine particles make up the majority of the number population of indoor submicrometer particles (on average $83 \%$ and $82 \%$ for indoors and outdoors, respectively). The $\mathrm{N}_{\mathrm{UFP}}$ and $\mathrm{N}_{\mathrm{FP}}$ diurnal cycles, also show similar overall trends. This indicated that in German residential environments, ultrafine particle number concentration level and variation observed from long-term measurements could represent those for submicrometer particles.

Notable contrasts can be seen in the diurnal cycle between the cold and warm seasons. These differences are obviously linked to the state of ventilation. In the cold season, ultrafine particles emitted from indoor sources caused the strong peaks in the diurnal cycle in indoor PNC. In the warm season, outdoor sources dominated the variation of the diurnal cycle of indoor submicrometer particles due to much longer periods of opening windows. The effects of indoor sources (cooking and combustion-related) are much more prominent compared with the warm season. Consequently, residents were exposed to different compositions of indoor particles. For better interpreting diurnal and seasonal variation, the residents' activities log is important.

It is necessary to measure both indoor and outdoor PNC and PNSD for better understanding of the dynamic behavior of indoor aerosols. During measurement periods, the median penetration factor was lower than 0.5 for any particle size within the range $10-800 \mathrm{~nm}$, and reflects that the typical German homes have building shells that are rather airtight and act as particle size-dependent filters for outdoor particles. However, due to the complexity of indoor particle dynamic processes and the varying ventilation rate in the real situation, the results of the particle loss rates and penetration factors can vary strongly between different housing situations. Nevertheless, our particle size-resolved real-time dataset makes detailed model validation possible, that not only covers the typical situation, but a broad range of housing situations. The diurnal and seasonal patterns in this study represent the typical patterns in German urban background homes. Moreover, the detailed, up-to-date dataset of indoor particle concentrations and size distributions in real-used homes can be used to estimate and/or determine the health effects of residential particle exposure in further studies.

\section{ACKNOWLEDGMENTS}

This work was supported by the Federal Ministry for the Environment, Nature Conservation, Building and Nuclear Safety (BMUB) grant UFOPLAN FKZ 371561200 (German title: ,Ultrafeine Partikel im Innenraum und in der Umgebungsluft: Zusammensetzung, Quellen und Minderungsmöglichkeiten"). We thank the 40 volunteering families, providing access to their homes for our measurements. We thank Niels Wollschläger, Anja Schmidt, Jacob Schacht, Thomas Müller (TROPOS) as well as Sabine Rust, Thomas Niemeyer, Konrad Neumann and Frank Riebel (UBA) for their helpful assistance during the laboratory and field experiment.

\section{SUPPLEMENTARY MATERIAL}

Supplementary data associated with this article can be found in the online version at http://www.aaqr.org.

\section{REFERENCES}

Abt, E., Suh, H.H., Catalano, P. and Koutrakis, P. (2000). Relative contribution of outdoor and indoor particle sources to indoor concentrations. Environ. Sci. Technol. 34: 3579-3587.

Allen, R., Larson, T., Sheppard, L., Wallace, L. and Liu, L.J.S. (2003). Use of real-time light scattering data to estimate the contribution of infiltrated and indoorgenerated particles to indoor air. Environ. Sci. Technol. 37: 3484-3492.

Alves, C.A., Calvo, A.I., Castro, A., Fraile, R., Evtyugina, M. and Bate-Epey, E.F. (2013). Indoor air quality in two university sports facilities. Aerosol Air Qual. Res. 13: 1723-1730.

Bhangar, S., Mullen, N., Hering, S., Kreisberg, N. and Nazaroff, W. (2011). Ultrafine particle concentrations and exposures in seven residences in northern California. Indoor Air 21: 132-144.

Brasche, S. and Bischof, W. (2005). Daily time spent indoors in German homes - Baseline data for the assessment of indoor exposure of German occupants. Int. J. Hyg. Environ. Health 208: 247-253.

Brook, R.D., Rajagopalan, S., Pope III, C.A., Brook, J.R., Bhatnagar, A., Diez-Roux, A.V., Holguin, F., Hong, Y., Luepker, R.V. and Mittleman, M.A. (2010). Particulate matter air pollution and cardiovascular disease: An update to the scientific statement from the American Heart Association. Circulation 121: 2331-2378.

Chen, C. and Zhao, B. (2011). Review of relationship between indoor and outdoor particles: I/O ratio, infiltration factor and penetration factor. Atmos. Environ. 45: 275-288.

Chen, G., Li, S., Zhang, Y., Zhang, W., Li, D., Wei, X., He, Y., Bell, M.L., Williams, G. and Marks, G.B. (2017). Effects of ambient $\mathrm{PM}_{1}$ air pollution on daily emergency hospital visits in China: An epidemiological study. The Lancet Planetary Health 1: e221-e229.

Custódio, D., Pinho, I., Cerqueira, M., Nunes, T. and Pio, C. 
(2014). Indoor and outdoor suspended particulate matter and associated carbonaceous species at residential homes in northwestern Portugal. Sci. Total Environ. 473: 72-76.

Diapouli, E. (2011). Indoor and outdoor particle number and mass concentrations in athens. sources, sinks and variability of aerosol parameters. Aerosol Air Qual. Res. 11: 632-642.

Geller, M.D., Chang, M., Sioutas, C., Ostro, B.D. and Lipsett, M.J. (2002). Indoor/outdoor relationship and chemical composition of fine and coarse particles in the southern california deserts. Atmos. Environ. 36: 1099-1110.

Hänninen, O., Lebret, E., Ilacqua, V., Katsouyanni, K., Künzli, N., Srám, R.J. and Jantunen, M. (2004). Infiltration of ambient $\mathrm{PM}_{2.5}$ and levels of indoor generated non-ets $\mathrm{pm}_{2.5}$ in residences of four European cities. Atmos. Environ. 38: 6411-6423.

Hassanvand, M.S., Naddafi, K., Faridi, S., Arhami, M., Nabizadeh, R., Sowlat, M.H., Pourpak, Z., Rastkari, N., Momeniha, F., Kashani, H., Gholampour, A., Nazmara, S., Alimohammadi, M., Goudarzi, G. and Yunesian, M. (2014). Indoor/outdoor relationships of $\mathrm{PM}_{10}, \mathrm{PM}_{2.5}$, and $\mathrm{PM}_{1}$ mass concentrations and their water-soluble ions in a retirement home and a school dormitory. Atmos. Environ. 82: 375-382.

He, C., Morawska, L. and Gilbert, D. (2005). Particle deposition rates in residential houses. Atmos. Environ. 39: 3891-3899.

Hussein, T., Hämeri, K., Heikkinen, M.S.A. and Kulmala, M. (2005). Indoor and outdoor particle size characterization at a family house in Espoo-Finland. Atmos. Environ. 39: 3697-3709.

Hussein, T. and Kulmala, M. (2008). Indoor Aerosol modeling: basic principles and practical applications. Water Air Soil Pollut. Focus 8: 23-34.

Hussein, T., Hruška, A., Dohányosová, P., Džumbová, L., Hemerka, J., Kulmala, M. and Smolík, J. (2009a). Deposition Rates on smooth surfaces and coagulation of aerosol particles inside a test chamber. Atmos. Environ. 43: 905-914.

Hussein, T., Kubincová, L., Džumbová, L., Hruška, A., Dohányosová, P., Hemerka, J. and Smolík, J. (2009b). Deposition of aerosol particles on rough surfaces inside a test chamber. Build. Environ. 44: 2056-2063.

Hussein, T., Dada, L., Juwhari, H. and Faouri, D. (2015). Characterization, fate, and re-suspension of aerosol particles $(0.3-10 \mu \mathrm{m})$ : The effects of occupancy and carpet use. Aerosol Air Qual. Res 15: 2367-2377.

Hussein, T. (2017). Indoor-to-outdoor relationship of aerosol particles inside a naturally ventilated apartment A comparison between single-parameter analysis and indoor aerosol model simulation. Sci. Total Environ. 596597: 321-330.

ICRP (1994). Human respiratory tract model for radiological protection. A Report of a Task Group of the International Commission on Radiological Protection. Ann. ICRP 24: 1-482.

Jones, N., Thornton, C., Mark, D. and Harrison, R. (2000). Indoor/outdoor relationships of particulate matter in domestic homes with roadside, urban and rural locations.
Atmos. Environ. 34: 2603-2612.

Koivisto, A.J., Kling, K.I., Hänninen, O., Jayjock, M., Löndahl, J., Wierzbicka, A., Fonseca, A.S., Uhrbrand, K., Boor, B.E. and Jiménez, A.S. (2019). Source specific exposure and risk assessment for indoor aerosols. Sci. Total Environ. 668: 13-24.

Liu, D.L. and Nazaroff, W.W. (2001). Modeling pollutant penetration across building envelopes. Atmos. Environ. 35: 4451-4462.

Liu, D.L. and Nazaroff, W.W. (2003). Particle penetration through building cracks. Aerosol Sci. Technol. 37: 565573.

Long, C.M., Suh, H.H. and Koutrakis, P. (2000). Characterization of indoor particle sources using continuous mass and size monitors. J. Air Waste Manage. Assoc. 50: $1236-1250$.

Long, C.M., Suh, H.H., Catalano, P.J. and Koutrakis, P. (2001). Using time-and size-resolved particulate data to quantify indoor penetration and deposition behavior. Environ. Sci. Technol. 35: 2089-2099.

Mahyuddin, N. and Awbi, H. (2012). A review of $\mathrm{CO}_{2}$ measurement procedures in ventilation research. Int. J. Vent. 10: 353-370.

Molnár, P., Gustafson, P., Johannesson, S., Boman, J., Barregård, L. and Sällsten, G. (2005). Domestic wood burning and $\mathrm{PM}_{2.5}$ trace elements: Personal exposures, indoor and outdoor levels. Atmos. Environ. 39: 26432653.

Molnár, P., Bellander, T., Sällsten, G. and Boman, J. (2007). Indoor and outdoor concentrations of $\mathrm{PM}_{2.5}$ trace elements at homes, preschools and schools in Stockholm, Sweden. J. Environ. Monit. 9: 348-357.

Monn, C., Fuchs, A., Högger, D., Junker, M., Kogelschatz, D., Roth, N. and Wanner, H.U. (1997). Particulate matter less than $10 \mu \mathrm{m}\left(\mathrm{PM}_{10}\right)$ and fine particles less than $2.5 \mu \mathrm{m}$ $\left(\mathrm{PM}_{2.5}\right)$ : Relationships between indoor, outdoor and personal concentrations. Sci. Total Environ. 208: 15-21.

Morawska, L., He, C., Hitchins, J., Gilbert, D. and Parappukkaran, S. (2001). The relationship between indoor and outdoor airborne particles in the residential environment. Atmos. Environ. 35: 3463-3473.

Morawska, L., Ayoko, G., Bae, G., Buonanno, G., Chao, C., Clifford, S., Fu, S.C., Hänninen, O., He, C. and Isaxon, C. (2017). Airborne particles in indoor environment of homes, schools, offices and aged care facilities: The main routes of exposure. Environ. Int. 108: 75-83.

Oberdörster, G. (2000). Pulmonary effects of inhaled ultrafine particles. Int. Arch. Occup. Environ. Health 74: $1-8$.

Odeh, I. and Hussein, T. (2016). Activity pattern of urban adult students in an eastern mediterranean society. Int. J. Environ. Res. Public Health 13: 960.

Ohlwein, S., Kappeler, R., Joss, M.K., Künzli, N. and Hoffmann, B. (2019). Health effects of ultrafine particles: A systematic literature review update of epidemiological evidence. Int. J. Public Health 64: 547-559.

Peters, A., Wichmann, H.E., Tuch, T., Heinrich, J. and Heyder, J. (1997). Respiratory effects are associated with the number of ultrafine particles. Am. J. Respir. Crit. Care 
Med. 155: 1376-1383.

Pitz, M., Cyrys, J., Karg, E., Wiedensohler, A., Wichmann, H.E. and Heinrich, J. (2003). Variability of apparent particle density of an urban aerosol. Environ. Sci. Technol. 37: 4336-4342.

Pope III, C.A. and Dockery, D.W. (2006). Health effects of fine particulate air pollution: Lines that connect. J. Air Waste Manage. Assoc. 56: 709-742.

Rim, D., Green, M., Wallace, L., Persily, A. and Choi, J.I. (2012). Evolution of ultrafine particle size distributions following indoor episodic releases: Relative importance of coagulation, deposition and ventilation. Aerosol Sci. Technol. 46: 494-503.

Rodes, C.E., Lawless, P.A., Thornburg, J.W., Williams, R.W. and Croghan, C.W. (2010). Dears particulate matter relationships for personal, indoor, outdoor, and central site settings for a general population. Atmos. Environ. 44: 1386-1399.

Rückerl, R., Schneider, A., Breitner, S., Cyrys, J. and Peters, A. (2011). Health effects of particulate air pollution: A review of epidemiological evidence. Inhalation Toxicol. 23: 555-592.

Schweizer, C., Edwards, R.D., Bayer-Oglesby, L., Gauderman, W.J., Ilacqua, V., Jantunen, M.J., Lai, H.K., Nieuwenhuijsen, M. and Künzli, N. (2007). Indoor timemicroenvironment-activity patterns in seven regions of Europe. J. Exposure Sci. Environ. Epidemiol. 17: 170 181.

Sun, J., Birmili, W., Hermann, M., Tuch, T., Weinhold, K., Spindler, G., Schladitz, A., Bastian, S., Löschau, G. and Cyrys, J. (2019). Variability of black carbon mass concentrations, sub-micrometer particle number concentrations and size distributions: RESULTS of the German Ultrafine Aerosol Network ranging from city street to High Alpine locations. Atmos. Environ. 202: 256-268.

Talbot, N., Kubelova, L., Makes, O., Cusack, M., Ondracek, J., Vodička, P., Schwarz, J. and Zdimal, V. (2016). Outdoor and indoor aerosol size, number, mass and compositional dynamics at an urban background site during warm season. Atmos. Environ. 131: 171-184.

Tian, L., Zhang, G., Lin, Y., Yu, J., Zhou, J. and Zhang, Q. (2009). Mathematical model of particle penetration through smooth/rough building envelop leakages. Build. Environ. 44: 1144-1149.
Turanjanin, V., Vučićević, B., Jovanović, M., Mirkov, N. and Lazović, I. (2014). Indoor $\mathrm{CO}_{2}$ measurements in serbian schools and ventilation rate calculation. Energy 77: 290-296.

WHO (2006). Air quality guidelines: Global update 2005: Particulate matter, ozone, nitrogen dioxide and sulfur dioxide, World Health Organization, Geneva.

Wiedensohler, A., Birmili, W., Nowak, A., Sonntag, A., Weinhold, K., Merkel, M., Wehner, B., Tuch, T., Pfeifer, S., Fiebig, M., Fjäraa, A.M., Asmi, E., Sellegri, K., Depuy, R., Venzac, H., Villani, P., Laj, P., Aalto, P., Ogren, J.A., Swietlicki, E., Williams, P., Roldin, P., Quincey, P., Hüglin, C., Fierz-Schmidhauser, R., Gysel, M., Weingartner, E., Riccobono, F., Santos, S., Grüning, C., Faloon, K., Beddows, D., Harrison, R., Monahan, C., Jennings, S.G., O'Dowd, C.D., Marinoni, A., Horn, H.G., Keck, L., Jiang, J., Scheckman, J., McMurry, P.H., Deng, Z., Zhao, C.S., Moerman, M., Henzing, B., de Leeuw, G., Löschau, G. and Bastian, S. (2012). Mobility particle size spectrometers: Harmonization of technical standards and data structure to facilitate high quality long-term observations of atmospheric particle number size distributions. Atmos. Meas. Tech. 5: 657-685.

Wiedensohler, A., Wiesner, A., Weinhold, K., Birmili, W., Hermann, M., Merkel, M., Müller, T., Pfeifer, S., Schmidt, A. and Tuch, T. (2018). Mobility particle size spectrometers: Calibration procedures and measurement uncertainties. Aerosol Sci. Technol. 52: 146-164.

Zhao, H. and Stephens, B. (2017). Using portable particle sizing instrumentation to rapidly measure the penetration of fine and ultrafine particles in unoccupied residences. Indoor Air 27: 218-229.

Zhao, J., Weinhold, K., Merkel, M., Kecorius, S., Schmidt, A., Schlecht, S., Tuch, T., Wehner, B., Birmili, W. and Wiedensohler, A. (2018). Concept of high quality simultaneous measurements of the indoor and outdoor aerosol to determine the exposure to fine and ultrafine particles in private homes. Gefahrstoffe Reinhalt. Luft 3: 73-78.

Received for review, December 9, 2019 Revised, December 3, 2019 Accepted, December 23, 2019 